\title{
HANDOVER SEBAGAI UPAYA PENINGKATAN KESELAMATAN PASIEN (PATIENT SAFETY) DI RUMAH SAKIT
}

\author{
Cecep Triwibowo ${ }^{1}$, Sulhah Yuliawati², Nur Amri Husna ${ }^{3}$ \\ 1 Jurusan Keperawatan Politeknik Kesehatan Kemenkes RI Medan \\ 2,3 Jurusan keperawatan Sekolah Tinggi IImu Kesehatan Mahardika Cirebon \\ email: cecep_triwibowo@yahoo.com
}

\begin{abstract}
Communication on various information about the patient's progress is a fundamental component in patient safety. Transfer information in handover is essential to ensure the effectiveness and safety in patient care. The purpose of this research is to know the a relationship between handover with patient safety. The methods of this research used analytic correlative with cross sectional approach. This research used total sampling that invited 62 nurses at Sidawangi Hospital West Java Province to participate. Collecting data using closed questionnaire. Data were analyzed using chi square. The result of research showed $53.2 \%$ nurses is implement handover included of good category and $51.6 \%$ patient safety included of good category. Statistical test showed a significant relationship between the implementation of the handover with patient safety in the hospital $(p 0.04)$. It concluded that that the handover contributes to patient safety in hospitals.
\end{abstract}

Keywords: Handover, Patient safety, Nurse

\begin{abstract}
ABSTRAK
Komunikasi terkait berbagai informasi tentang kondisi pasien merupakan komponen dasar pada patient safety. Transfer informasi pada handover merupakan hal yang penting untuk menjamin efektivitas dan keamanan pada perawatan pasien. Tujuan dari penelitian ini yaitu untuk mengetahui hubungan antara handover dengan patient safety. Penelitian ini merupakan analitik korelasi dengan pendekatan cross sectional. Penelitian ini menggunakan total sampling dengan mengundang 62 perawat di Rumah Sakit Sidawangi Provinsi Jawa Tengah untuk terlibat. Pengumpulan data menggunakan kuisioner tertutup. Analsis data menggunakan uji Chi Square. Hasil penelitian menunjukkan $53,2 \%$ perawat melaksanakan handover dengan baik dan 51,6 \% patient safety termasuk kategori baik. Hasil uji Chi Square terdapat hubungan yang signifikan antara pelaksanaan handover patient safety di rumah sakit $(p 0,04)$. Kesimpulan bahwa handover berkontribusi terhadap patient safety di rumah sakit.
\end{abstract}

Kata Kunci: Handover, Patient Safety, Perawat 


\section{PENDAHULUAN}

Patient safety merupakan prioritas, isu penting dan global dalam pelayanan kesehatan (Perry 2009). Ballard (2003) dalam Mustikawati (2011) menyatakan bahwa Patient safety merupakan komponen penting dan vital dalam asuhan keperawatan yang berkualitas. Hal ini menjadi penting karena Patient safety merupakan suatu langkah untuk memperbaiki mutu pelayanan dalam memberikan asuhan keperawatan (Cahyono, 2008). Inti dari patient safety yaitu penghindaran, pencegahan dan perbaikan dari kejadian yang tidak diharapkan atau mengatasi cedera-cedera dari proses pelayanan kesehatan (Ballard, 2003). Sehingga, program utama patient safety yaitu suatu usaha untuk menurunkan angka kejadian tidak diharapkan (KTD) yang sering terjadi pada pasien selama dirawat di rumah sakit yang sangat merugikan baik pasien maupun pihak rumah sakit.

Menurut JCAHO (2007), $65 \%$ dari KTD yang terjadi dirumah sakit berdampak pada kematian pasien. Menurut KKP-RS (2010), insiden KTD di Indonesia mencapai 46,67\% dengan provinsi jawa barat menempati urutan tertinggi yaitu $33.33 \%$, dan berurutan provisi Banten sebesar 20.0\%, Jawa Tengah sebesar 20.0\%, DKI Jakarta sebesar $16.67 \%$, Bali sebesar $6.67 \%$, dan Jawa Timur sebesar 3.33\% .

$$
\text { Angood (2007) dalam Dewi }
$$

(2012) mengungkapkan bahwa berdasarkan hasil kajian data penyebab utama KTD di rumah sakit adalah komunikasi. Alvarado (2006) mengungkapkan bahwa ketidakakuratan informasi dapat menimbulkan dampak yang serius pada pasien, hampir $70 \%$ kejadian sentinel (kejadian yang mengakibatkan kematian atau cedera serius di rumah sakit) disebabkan karena buruknya komunikasi.

Komunikasi terhadap berbagai informasi mengenai perkembangan pasien antar profesi kesehatan di rumah sakit merupakan komponen yang fundamental dalam perawatan pasien (Riesenberg,2010). Transfer informasi pada saat pergantian shift yang disebut dengan handover bertujuan untuk menyampaikan informasi dari setiap pergantian shift serta memastikan efektifitas dan keamanan dalam perawatan pasien. Informasi terkait dengan keadaan klinis pasien, kebutuhan pasien, keadaan personal pasien, sampai pada faktor sosial pasien. Perawat harus datang minimal 15 menit lebih awal untuk mengikuti handover sehingga proses handover dapat berjalan lancar (McCLoughen et al., 2008 dalam Scovell, 2010).

\section{METODE}

Penelitian ini merupakan penelitian kuantitatif, menggunakan metode penelitian analitik korelatif dengan pendekatan cross sectional, sampel yang digunakan adalah total sampling dengan seluruh jumlah dari populasi yaitu 62 perawat, penelitian ini dilakukan di Rumah Sakit Paru Sidawangi Provinsi Jawa Barat. Pengumpulan data menggunakan kuesioner tertutup. Kuesioner dilakukan untuk mengetahui gambaran perawat tentang pelaksanaan handover dengan patient safety. Kuesioner penelitian dalam penyusunan dikembangkan sendiri oleh peneliti, dan merujuk pada kuesioner handover yang diambil dari Elisabet (2012), sedangkan kuesioner patient safety diambil dari Atisah (2012). Analisa data univariat dan bivariat menggunakan program SPSS dan uji statistik yang digunakan yaitu Chi Square. 
HASIL DAN PEMBAHASAN

Pelaksanaan Handover

Berdasarkan tabel 1 diketahui bahwa pada pelaksanaan handover sebagian besar perawat yaitu 53,2 \% melaksanakan operan dengan baik dan tidak baik sebesar $46,8 \%$. maka terdapat hubungan antara pelaksanaan handover dengan Patient safety. Baik buruknya pelaksanaan handover dapat mempengaruhi patient safety.

Elisabet (2008) menyatakan bahwa baik buruknya pelaksanaan

Tabel 1. Kondisi Handover dan Patient Safety di Ruang Rawat Inap

\begin{tabular}{ll}
\hline Variabel & $\mathbf{n}(\%)$ \\
\hline Hand Over & \\
Baik & $33(53,2)$ \\
Tidak Baik & $29(46,8)$ \\
Patient Safety & \\
Baik & $32(51,6)$ \\
Tidak baik & $30(48,4)$
\end{tabular}

\section{Patient safety}

Berdasarkan tabel 1 diketahui bahwa patient safety oleh perawat terhadap pasien pada kategori baik dengan persentase $51.6 \%$ dan tidak baik sebesar $48,4 \%$. handover ditunjang dengan adanya Standar Operasional Prosedur (SOP) dimana dalam SOP harus mencerminkan $4 \mathrm{~W}+1 \mathrm{H}$ (what, who, when, where, how) sehingga dapat menimbulkan kesinambungan dalam memberikan

Tabel 2 Hubungan Handover dan Patient Safety di Ruang Rawat Inap

\begin{tabular}{|c|c|c|c|c|}
\hline \multirow{2}{*}{ Variabel } & \multicolumn{2}{|c|}{ Handover } & \multirow[t]{2}{*}{ Total } & \multirow[t]{2}{*}{$p$} \\
\hline & Baik & Tidak Baik & & \\
\hline \multicolumn{5}{|l|}{ Patient safety } \\
\hline $\begin{array}{l}\text { Baik } \\
\text { Tidak Baik }\end{array}$ & $\begin{array}{l}21,0 \\
32,2\end{array}$ & $\begin{array}{l}30,6 \\
16,2\end{array}$ & $\begin{array}{l}51,6 \\
48,4\end{array}$ & 0,04 \\
\hline Total & 53,2 & 46,8 & 100,0 & \\
\hline
\end{tabular}

\section{Hubungan Pelaksanaan Handover Dengan Patient safety}

Berdasarkan tabel 2 diperoleh hasil bahwa, $P$ value didapatkan 0,04 artinya terdapat hubungan yang signifikan antara pelaksanaan handover dengan Patient safety. Hal ini karena 0,040 lebih kecil dari $0,05(P \leq 0,05)$ dapat disimpulkan bahwa Ho ditolak dan $\mathrm{Ha}$ diterima, artinya antara kedua variabel terdapat hubungan.

Berdasarkan hasil penelitian didapatkan nilai $P$ value $\leq 0,05(0,04)$, informasi secara cepat dan akurat tentang kondisi pasien dan proses keperawatan yang diberikan. Menurut Alvarado et al. (2006) adanya standar komunikasi efektif yang terintegrasi dengan keselamatan pasien dalam handover dan disosialisasikan secara menyeluruh pada perawat pelaksana akan meningkatkan efektifitas dan koordinasi dalam mengkomunikasikan informasi penting sehingga meningkatkan kesinambungan pelayanan dalam mendukung patient 
safety. Sejalan dengan teori llyas (2003) sosialisasi dapat meningkatkan wawasan dan pengetahuan yang menjadi dasar motivasi seseorang untuk melakukan serangkaian kegiatan dengan bekerja keras dan cerdas, demi mencapai tujuan tertentu.

Menurut penelitian yang dilakukan O'Connell et al., (2008) dalam AMA (2006) mengungkapkan bahwa di Australia komunikasi yang buruk sebagai faktor penyebab dalam sekitar $20-25 \%$ dari kejadian sentinel. Sedangkan menurut penelitian yang dilakukan Kamil (2011) handover yang tidak efektif dapat berkontribusi terhadap kesalahan dan pelanggaran dalam keselamatan perawatan pasien, termasuk kesalahan pengobatan, salah operasi, dan kematian pasien. Sedangkan menurut Alvarado et al., (2006) bahwa komunikasi yang diberikan perawat dalam pertukaran shift (operan) sangat membantu dalam perawatan pasien dan buruknya komunikasi dapat mengakibatkan kematian atau cedera yang serius di rumah sakit. Handover yang tidak berjalan dengan baik dapat mempengaruhi perawatan (Wong et al, 2008 dalam AHHA, 2009)

Menurut penelitian yang dilakukan oleh Hughes (2008) dalam Kamil (2011) mengungkapkan bahwa faktor pelaksanaan handover tidak berjalan dengan baik disebabkan oleh faktor eksternal dan internal individu dan organisasi. Dewi (2012) mengatakan bahwa keselamatan pasien terlindungi melalui standar keselamatan pasien dan peningkatan penerapan keselamatan pasien oleh perawat dikarenakan adanya penerapan keselamatan diantaranya pengidentifikasian pasien, komunikasi efektif pada saat timbang terima, menghindari kesalahan pemberian obat, meniadakan kesalahan prosedur tindakan, mencegah infeksi nosokomial, serta pencegahan pasien jatuh. Sejalan dengan penelitian Johnson (2006) dalam Dewi (2012) bahwa adanya prosedur handover yang efektif dalam meningkatkan kesinambungan, kualitas serta keselamatan dalam memberikan pelayanan pada pasien.

\section{KESIMPULAN}

Gambaran pelaksanaan handover oleh perawat di Ruang Rawat Inap Rumah Sakit Paru Sidawangi Provinsi Jawa Barat termasuk kategori baik. Gambaran patient safety di Ruang Rawat Inap Rumah Sakit Paru Sidawangi Provinsi Jawa Barat yaitu termasuk dalam kategori baik. Hasil analisis menunjukkan terdapat hubungan yang bermakna antara pelaksanaan handover dengan patient safety di Ruang Rawat Inap Rumah Sakit Paru Sidawangi Provinsi Jawa Barat. Handover yang baik berkontribusi terhadap peningkatan patient safety.

\section{SARAN}

Rumah Sakit agar melakukan evaluasi tentang pelaksanaan handover dan evaluasi tentang pelaporan dan analisis insiden keselamatan pasien serta melakukan pelatihan tentang handover untuk menunjang pelayanan yang optimal. Perawat diharapkan dapat mempertahankan komunikasi dan kerjasama antar perawat di ruangan serta dapat meningkatkan kesadaran, kejujuran dan keterbukaan dalam melindungi patient safety. Kepada peneliti selanjutnya agar dapat dilakukan penelitian mendalam tentang pelaksanaan handover dengan patient safety dengan metode observasi. 


\section{KEPUSTAKAAN}

AHHA (Australian Healthcare \& Hospitals Association). (2009). Clinical handover: system cange, leadership and principles.

AMA (Australian Medical Association). (2006). Safe handover: Safe patient. Alvarado, K., Lee, R., Christoffersen, E., Fram, N., Boblin, S., Poole, N., ... \& Forsyth, S. (2006). Transfer of accountability: transforming shift handover to enhance patient safety. Healthcare Quarterly, 9(Sp).

Atisah. (2012). Hubungan antara pelayanan keperawatan profesional dengan penerapan patient safety di instalasi intensif Rumah Sakit Gunung Jati Cirebon. Skripsi. Stikes Mahardika Cirebon.

Cahyono, J.B. (2008). Membangun budaya keselamatan pasien dalam praktik kedokteran. Yogyakarta: Kanisius.

Dewi, M. (2012). Pengaruh pelatihahan timbang terima pasien terhadap penerapan keselamatan pasien oleh perawat pelaksana di RSUD Raden. Jurnal Health \& Sport, 5 (3).

Elisabet. (2008). Optimalisasi pelaksanaan handover berdasarkan standar national patient safety. Jurnal
Administrasi dan Kebijakan Kesehatan, 6:166-171.

llyas, Y. (2003). Kiat sukses manajemen tim kerja. Jakarta: PT. Gramedia Pustaka Utama.

JCAHO. (2007). Patien safety matters information and communication. Spesial Isuue, 2 (1).

Kamil, H. (2011). Handover dalam pelayanan keperawatan. Volume 4 No. 11 (102-116).

KKP-RS. (2008). Panduan nasional keselamatan pasien rumah sakit. Jakarta: Depkes RI.

Mustikawati. (2011). Analisis determinan kejadian nyaris cedera dan kejadian tidak di harapkan di unit perawatan Rumah Sakit Pondok Indah Jakarta. Skripsi. Universitas Indonesia Jakarta.

Riesenberg, A, L., Leitzsch, J., \& Cunningham, M. (2010). Nursing handoffs: A systemic review of the literature: surprisingly little is known about what constitutes best practice. American Journal of Nursing, 110(4): 24-34.

Scovell, S. (2010). Role of the nurse to nurse handover in patient care. Nursing Standard, 24(30): 35- 3. 